\title{
Fetal atrial septal aneurysm: a differential diagnosis of aortic arch retrograde flow
}

\author{
Ana Cláudia Santos, ${ }^{1,2}$ Miguel Branco, ${ }^{1}$ Paula Martins ${ }^{3}$
}

'Maternidade Bissaya Barreto, Centro Hospitalar e Universitário de Coimbra, Coimbra, Portugal ${ }^{2}$ Obstetrics and Gynaecology Department, Centro Hospitalar do Baixo Vouga, Aveiro, Portugal ${ }^{3}$ Paediatric Cardiology Department, Hospital Pediátrico de Coimbra, Centro Hospitalar e Universitário de Coimbra, Coimbra, Portugal

\section{Correspondence to}

Dr Ana Cláudia Santos; aclaudiapsantos@gmail.com

Accepted 13 December 2019

\section{DESCRIPTION}

A 28-year-old healthy woman, with two previous pregnancies with no intercurrences and healthy children, was send to our prenatal diagnosis centre due to a suspicion of congenital heart disease (CHD) at the third trimester. Actual pregnancy uneventful but with late beginning of fetal-maternal surveillance, at the second trimester. At the fetal ultrasound, she presented: thymus size above the 90th percentile; discrete chambers disproportion, with a smaller left side; an atrial septal aneurysm

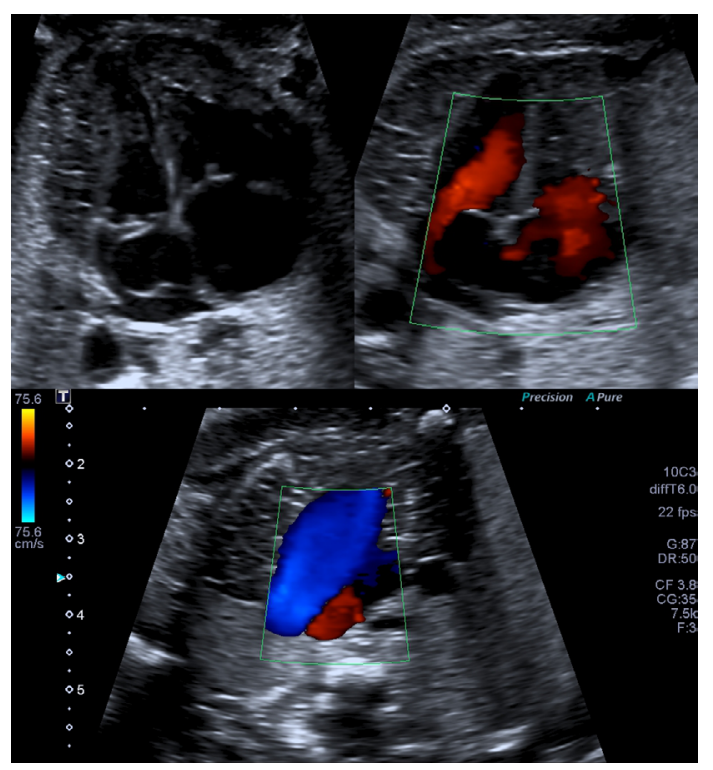

Figure 1 Top left: 4 chamber view (4CV) - the atrial septal aneurysm; discrete chambers disproportion, with predominant right chambers. Top right: colour Doppler in 4CV - limited flow through the mitral valve. Bottom: 3 vessel trachea (3VT) view - retrograde flow in the aortic arch.

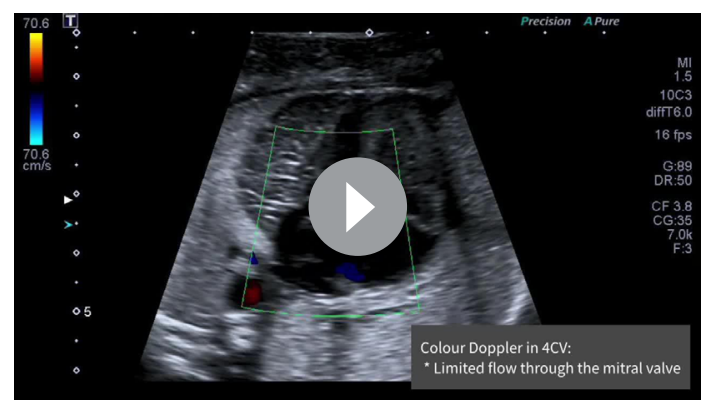

Video 1 Fetal atrial septal aneurysm. First segment: 4 chamber view (4CV); second segment: colour Doppler in 4CV; third segment: 3 vessel trachea view; and fourth segment: aortic arch sagittal view.
(ASA) (figure 1; video 1); a complete aortic arch, apparently without narrowing but with retrograde flow in 3 VT (figure 1; video 1) and sagittal views and a conditioned left atrioventricular (AV) flow (figure 1; video 1), seemingly due to the aneurysmatic bulging into the left atrium. Ultrasound surveillance was made every 2 weeks, with no significant changes till delivery, which was vacuumassisted at 39 weeks. The newborn was $3395 \mathrm{~g}$, had an Apgar index of 9/10. He stayed at the neonatal intensive care unit because of the suspicion of CHD and for foramen ovale closure surveillance. CHD was not confirmed, with the only altered echocardiographic finding being patent foramen ovale. He was dismissed at the sixth day of life. At the third month of cardiology appointment, he was asymptomatic, with normal growing curves. Ecocardiographic evaluation showed proportional cardiac chambers, a restrictive ostium secundum atrial septal defect, with no other abnormalities and the eletrocardiographic evaluation was normal. A follow-up appointment was scheduled for the second year of life.

In this report, we present fetal ultrasound images of retrograde flow in the aortic arch and cardiac chambers disproportion, with predominant right chambers (figure 1; video 1). Considering these findings, especially the first, differential diagnosis includes, mainly, causes of severe left side structural heart disease, such as hypoplastic left heart, aortic stenosis/atresia or aortic coarctation, with this last hypothesis being of difficult prenatal exclusion. ${ }^{12}$ In this case, the only cardiac finding, besides the previously mentioned, was an ASA with no other structural abnormality.

ASA is an abnormal large structure at the level of the foramen ovale that corresponds to a redundant septum primum which has an excessive excursion into the left atrium. The information regarding this finding in the fetus is scarce. Frequently it is described as an uncommon condition, although in one large study a prevalence of $7.6 \%$ was reported. ${ }^{3}$ An association between ASA and arrhythmias have been reported in several studies, with some reports identifying an unexpected high incidence (up to $70 \%$ ) of ASA in fetuses referred for evaluation of arrhythmias. ${ }^{45}$ However, ASA usually is not a pathological condition, being self-limited, with some authors defending that it should be considered benign and transient. ${ }^{3}$ Nevertheless, in cases where there is a severe bulging of the redundant septum primum into the left atrium, it can cause a compromise to the flow through the mitral valve, creating the appearance of ventricular disproportion, with a 


\section{Learning points}

- Aortic arch retrograde flow is a predictor of a left side structural heart disease, usually associated with a reserved prognosis.

- It is important to keep in mind the possibility for other diagnosis with different prognosis, such as the atrial septal aneurysm, an usually benign cardiac finding.

- ASA is an hypothesis that should be considered and excluded due to its implications in prenatal diagnosis counselling, as it can mimic a left side structural heart disease.

small left ventricle. This flow compromise can be significant to the point of causing a retrograde flow in the aortic arch, raising the suspicion of an important left side cardiac structural disease. After delivery, in most of the cases, because of the physiological vascular modifications, there is a normalisation of the ventricular size and a repositioning of the atrial septum. ${ }^{6}$

Contributors All authors have read and approved the manuscript. All authors contributed to the work according to ICMJE requirements for authorship. All authors declare that the manuscript is an original work that has not been submitted to another journal or conference. ACS was responsible for planning, conception, bibliographic research, reporting, design and interpretation of data. MB was responsible for planning, conduct, conception, acquisition of data and interpretation of data. PM was responsible for planning, conception, conduct and interpretation of data

Funding The authors have not declared a specific grant for this research from any funding agency in the public, commercial or not-for-profit sectors.

Competing interests None declared.

Patient consent for publication Obtained.

Provenance and peer review Not commissioned; externally peer reviewed.

\section{REFERENCES}

1 Viñals F, Heredia F, Giuliano A, et al. The role of the three vessels and trachea view (3VT) in the diagnosis of congenital heart defects. Ultrasound Obstet Gynecol 2003:22:358-67.

2 Quartermain MD, Cohen MS, Dominguez TE, et al. Left ventricle to right ventricle size discrepancy in the fetus: the presence of critical congenital heart disease can be reliably predicted. J Am Soc Echocardiogr 2009;22:1296-301.

3 Ozcelik N, Atalay S, Tutar E, et al. Prevalence of interatrial septal aneurysm in newborns and their natural course. Pediatr Cardiol 2006;27:343-6.

4 Toro L, Weintraub RG, Shiota T, et al. Relation between persistent atrial arrhythmias and redundant septum primum flap (atrial septal aneurysm) in fetuses. Am J Cardiol 1994:73:711-3.

5 Stewart PA, Wladimiroff JW. Fetal atrial arrhythmias associated with redundancy/ aneurysm of the foramen ovale. J Clin Ultrasound 1988;16:643-50.

6 Channing A, Szwast A, Natarajan S, et al. Maternal hyperoxygenation improves left heart filling in fetuses with atrial septal aneurysm causing impediment to left ventricular inflow. Ultrasound Obstet Gynecol 2015;45:664-9.

Copyright 2020 BMJ Publishing Group. All rights reserved. For permission to reuse any of this content visit

https://www.bmj.com/company/products-services/rights-and-licensing/permissions/

BMJ Case Report Fellows may re-use this article for personal use and teaching without any further permission.

Become a Fellow of BMJ Case Reports today and you can:

- Submit as many cases as you like

- Enjoy fast sympathetic peer review and rapid publication of accepted articles

- Access all the published articles

Re-use any of the published material for personal use and teaching without further permission

Customer Service

If you have any further queries about your subscription, please contact our customer services team on +44 (0) 2071111105 or via email at support@bmj.com.

Visit casereports.bmj.com for more articles like this and to become a Fellow 